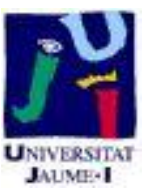

Título artículo / Títol article: Emotional Reactivity during anticipation and perception of affective pictures

Autores / Autors

Pastor Verchili, María del Carmen ; Poy Gil, Roser ; Segarra, Pilar ; Moltó Brotons, Javier

Revista:

The Spanish Journal of Psychology, 2014, 17

Versión / Versió:

Postprint de l'autor

Cita bibliográfica / Cita bibliogràfica (ISO 690):

PASTOR, M. Carmen, et al. Emotional Reactivity during Anticipation and Perception of Affective Pictures. The Spanish Journal of Psychology, 2014, 17: E110.

url Repositori UJI: http://hdl.handle.net/10234/126185 


\section{The Spanish Journal of Psychology}

Date of delivery: $15-12-2014$

\begin{tabular}{l|l|l|} 
Journal and vol/article ref: & s.jp & S1138741614001061
\end{tabular}

Number of pages (not including this page): 10

This proof is sent to you on behalf of Cambridge University Press. Please print out the file and check the proofs carefully. Please ensure you answer all queries.

Please EMAIL your corrections within

2 days of receipt to:

\section{Ana Montero <psyjourmanaging@psi.ucm.es>}

Authors are strongly advised to read these proofs thoroughly because any errors missed may appear in the final published paper. This will be your ONLY chance to correct your proof. Once published, either online or in print, no further changes can be made.

NOTE: If you have no corrections to make, please also email to authorise publication.

- The proof is sent to you for correction of typographical errors only. Revision of the substance of the text is not permitted, unless discussed with the editor of the journal. Only one set of corrections are permitted.

- Please answer carefully any author queries.

- Corrections which do NOT follow journal style will not be accepted.

- A new copy of a figure must be provided if correction of anything other than a typographical error introduced by the typesetter is required.

- If you have problems with the file please email psyjourmanaging@psi.ucm.es

Please note that this pdf is for proof checking purposes only. It should not be distributed to third parties and may not represent the final published version.

Important: you must return any forms included with your proof. We cannot publish your article if you have not returned your signed copyright form

\section{Please do not reply to this email}

NOTE - for further information about Journals Production please consult our FAQs at http://journals.cambridge.org/production_faqs 


\section{Author Queries}

QA $\quad$ The distinction between surnames can be ambiguous, therefore to ensure accurate tagging for indexing purposes online (eg for PubMed entries), please check that the highlighted surnames have been correctly identified, that all names are in the correct order and spelt correctly. 


\title{
Emotional Reactivity during Anticipation and Perception of Affective Pictures
}

\author{
M. Carmen Pastor, Rosario Poy, Pilar Segarra and Javier Moltó
}

Universitat Jaume I (Spain)

\begin{abstract}
The focus of the present study was on further exploring anticipatory responses to emotional stimuli by measuring the eyeblink startle reflex in a variation of the picture-picture affective learning procedure. Participants (113 undergraduate women) were not explicitly instructed before the experiment began. Instead, they had to learn the specific relations between cues (geometrical shapes) and emotional pictures based on pairings during the first part of the task. Plausible contingency learning effects were tested afterwards, in a parallel sequence of trials including auditory probes during cues and pictures processing during the second part of the task. Results did show the typical affective startle modulation pattern during perception, linear $F(1,200)=52.67, p<.0001$, but unexpected inhibition for both pleasant and unpleasant, compared to neutral cues, during anticipation, quadratic $F(1,200)=7.07, p<.009$. All patterns of startle modulation were independent of cue-picture contingency awareness (all interactions $F \mathrm{~s}<1$ ). Skin conductance changes showed the predictable quadratic trend either during picture perception or anticipatory periods (greater activity for emotional vs. neutral; overall quadratic $F(1,224)=7.04, p<.01)$, only for participants fully aware of the cuepicture contingency, quadratic $F(1,158)=5.86, p<.02$. Overall, our results during anticipation (cues processing) seem to suggest that more resources were allocated to highly arousing pictures that engage attention. Differences between the present results and prior research may be attributed to procedural variations in the sample, cues, or instructions. Future studies should also explore in more detail the role of the contingency awareness during anticipation.
\end{abstract}

Received 25 November 2013; Revised 21 April 2014; Accepted 23 June 2014

Keywords: emotion, anticipation, startle reflex, skin conductance, affective pictures.

The human startle reflex, the involuntary response to a sudden onset stimulus, has received much research interest among psychophysiologists because it can serve as a probe into both affective and cognitive processes (Dawson, Schell, \& Böhmelt, 1999). In a number of studies, magnitude of the startle reflex is reliably augmented during perception of unpleasant, compared to pleasant stimuli, either when people view pictures or films, listen to sounds, or smell odors (for a review, see Bradley, Cuthbert, \& Lang, 1999). Affective modulation of startle reflex during perception is a highly stable and replicable finding that has been explained according to the motivational priming hypothesis (Lang, Bradley, \& Cuthbert, 1997), in which activation of the defensive motivational system by an unpleasant stimulus primes related reflexes, such as the startle response. Conversely, activation of the appetitive system by pleasant stimuli inhibits this reflex response, reducing its magnitude.

Correspondence concerning this article should be addressed to M. Carmen Pastor. Department of Basic and Clinical Psychology, and Psychobiology Universitat Jaume I. Avenida Sos Baynat s/n. 12071. Castellón de la Plana (Spain). Phone (office): +34-964729977. Fax: +34-964729267.

E-mail: mpastor@psb.uji.es

The authors would like to thank Margaret M. Bradley for her helpful comments during the preparation of this manuscript, and for her assistance with data analyses and interpretation of the current results.
The startle reflex has also been used to study emotional responses in the context of anticipation, a cognitive process that occurs when one stimulus signals the imminence of an emotional event. Some studies refer to anticipation as "expectancy" of future events that allows one to optimize the speed and accuracy of identification of motivationally relevant information, and its translation into prompt actions, which are critical for survival (e.g., Bermpohl et al., 2006). Expectancy may be regarded as preceding attention to an upcoming stimulus that is predicted by a contextual cue. Previously acquired knowledge, in combination with current environmental information, provides the basis for the generation of expectancy (Pavlov \& Anrep, 1927). Anticipation can also be observed in a variety of domains, including vision, somatosensation, reward, and emotion. Emotional expectancy, indeed, concerns the anticipation of emotionally salient events, which prepares for focused affective and cognitive information processing, as well as for early motor and autonomic reactions (Bermpohl et al., 2006).

The experimental findings using the startle reflex paradigm have generally shown that blink magnitude is similarly enhanced when anticipating a variety of aversive events, such as intense noise blasts (Patrick \& Berthot, 1995; Skolnick \& Davidson, 2002), or electric shocks (Bradley, Moulder, \& Lang, 2005; Bradley, 
Silakowski, \& Lang, 2008; Grillon, Ameli, Merikangas, Woods, \& Davis, 1993; Grillon, Ameli, Woods, Merikangas, \& Davis, 1991; Grillon \& Davis, 1995; Poy et al., 2007). In most of these studies, however, pleasant stimulation was not included, due in part to difficulties in identifying an arousing appetitive stimulus that is in the same modality and is also of sufficient salience to maintain anticipatory responses across repeated presentations. Therefore, prior research did not clarify whether enhanced blink responses during anticipation is an effect of stimulus aversiveness per se or stimulus arousal.

To this extent, in the last years different laboratories have explored startle reflex during anticipation of highly arousing unpleasant or pleasant pictures. Despite important methodological differences across studies, findings have generally shown that blink responses are enhanced when anticipating maximally arousing pictures (either pleasant or unpleasant) compared to neutral stimuli, when participants were verbally instructed about cues-affective picture relationship before performing the task (e.g., Dichter, Tomarken, \& Baucom, 2002; Lipp, Cox, \& Siddle, 2001; Nitschke et al., 2002; Sabatinelli, Bradley, \& Lang, 2001; Sege, Bradley, \& Lang, 2011). Similarly, within the emotional imagery paradigm, the acoustic startle reflex has generally found to be greater for highly arousing emotions, with both aversive and pleasant scripts exceeding neutral and low arousing scenarios (e.g., McTeague et al., 2010; Miller, Patrick, \& Levenston, 2002; Witvliet \& Vrana, 2000). In the same way, results in a differential picturepicture affective learning procedure with pairings of shapes (CS) and emotional pictures (UCS) have shown that post-acquisition blink reflexes were larger during pleasant and unpleasant CS compared to neutral CS (e.g., Mallan \& Lipp, 2007; Mallan, Lipp, \& Libera, 2008). Taken together, all these studies have provided evidence that eyeblink startle potentiation accompanying anticipatory processes is modulated by the emotional arousal of anticipating pictures varying in emotional content.

However, a small number of studies have also suggested that picture aversiveness could contribute to the startle reflex potentiation above and beyond the effects of emotional arousal. In a paradigm using simple warning symbols to predict the unpleasant, pleasant, or neutral content of ensuing pictures, Nitschke et al. (2002) found larger startle responses for unpleasant than for pleasant pictures, suggesting an emotional modulation in addition to that explained by stimulus arousal. Furthermore, Allen, Wong, Kim, and Trinder (1996) and Erickson, Levenson, Curtin, Goff, and Patrick (1995) presented participants with pairings of tones that differed in pitch with pleasant, neutral or aversive pictures, and found that blink magnitude elicited during the tone stimuli increased linearly with the aversiveness of the anticipated picture, consistent with an affect startle effect. During emotional imagery, likewise, similar findings of greater startle responses for unpleasant (fear), compared to pleasant scripts (joy) have been reported, suggesting that both valence and arousal are important in affective matching during imagery (Witvliet \& Vrana, 2000). In the context of the threat-of-shock paradigm, moreover, smaller startle responses during signals of safety in comparison to signals of aversive stimulation or a no-signal context condition have also been reported (e.g., Grillon \& Ameli, 1998). On the other hand, some other studies failed to find any difference in blink magnitude during picture anticipation (Cook, David, Hawk, Spence, \& Gautier, 1992; see Lipp et al., 2001), or during acquisition trials in a picture-picture learning task, where novel shapes (CS) were paired with valenced and neutral pictures (UCS), either in a forward or a backward conditioning design (Mallan et al., 2008).

Consequently, prior research using pictures as emotionally salient, anticipated stimuli led to equivocal results that seem difficult to integrate, especially those related to pleasant attenuation vs. potentiation during anticipation, which might be explained by a number of procedural differences across studies. The purpose of this study was to re-examine the processing mediating anticipation of affective stimuli by measuring the eyeblink startle reflex and skin conductance changes to disentangle the role of stimulus aversiveness (affective modulation) and emotional arousal (attentional modulation) over anticipatory responses. A geometrical shape (a triangle, a square, or a circle) signaled whether the upcoming picture would portray unpleasant (threat), pleasant (erotica), or neutral (household objects) pictures during each 6-s anticipatory period. Immediately afterwards, the picture was presented for 6-s, and acoustic probes were presented in the latter half of the anticipation or perception periods. An important methodological difference between this study and prior research on anticipation of affective pictures or emotional imagery was that participants were not explicitly instructed about which one of the three geometrical shapes would depict the upcoming emotional category (erotica, neutral, threatening scenes). Therefore, the expectancy cues could be defined as "uncertain" in that here we did not provide a priori specific information about the cue-picture contingency at the start of the experiment. By contrast, participants were expected to learn this relationship throughout pairings of cues and pleasant, neutral, or unpleasant pictures during the first half of the task, similarly to what happens in the real life, thus providing ecological validity to this experimental task. 
Our design resembles the picture-picture affective learning task introduced by Lipp and colleagues (cf. Mallan \& Lipp, 2007; Mallan et al., 2008), in that 6-s of novel shapes were paired with 6-s of affective or neutral pictures without verbal instructions about explicit contingencies. Nonetheless, instead of testing conditioning effects over the extinction trials where cues are usually presented alone (cf. Mallan et al., 2008), we used a set of cues-pictures pairings as learning (nonprobed) trials during the first half of the task, followed by a second set of pairings where auditory probes were delivered to examine the effects of emotional valence and arousal over anticipatory startle reflex modulation likewise prior investigation focused on anticipation of affective material.

A linear relationship between picture valence and startle magnitude was predicted during perception of affective pictures, with larger responses during viewing of unpleasant, compared to pleasant, pictures. When anticipating emotional pictures, we tested whether blink startle potentiation would be found for both pleasant and unpleasant pictures - due to the emotional arousal-, or specifically for unpleasant stimuli confirming that the aversive nature of such anticipation further contributes to the startle potentiation. Larger electrodermal responses have been found when anticipating (Sabatinelli et al., 2001; Simons, Öhman, \& Lang, 1979), or perceiving (Lang, Greenwald, Bradley, \& Hamm, 1993) emotional arousing stimuli, in comparison with neutral material. In our study, the pattern of autonomic responses and affective ratings over pictures were expected to be similar to those reported in prior research. For both startle responses and electrodermal changes, additionally, we carefully evaluated whether contingency awareness of the cue-picture relationships might moderate the physiological pattern of reactivity during anticipation of emotional material.

\section{Method}

\section{Participants}

Hundred-and-thirteen undergraduate women from Universitat Jaume I (Castellón de la Plana, Spain), ranging between 18 and 44 years $(M=21.91$; $S D=$ 3.52), participated in this study as part of course requirement ${ }^{1}$. Because of equipment or experimenter errors, some data were lost for some participants leaving 110 females for the analysis of affective ratings, 101 for the

\footnotetext{
${ }^{1}$ Though our original sample also included 13 men (due to difficulties to recruit more men in this particular Psychology course), we finally decided to exclude them from the analyses reported here. The gender disproportion in the final sample precluded us from testing validly gender differences in the anticipation and perception patterns found in the sample as a whole, thus making it difficult to support a valid generalization of the results across gender.
}

analysis of startle reflex, and 113 for the analysis of skin conductance changes.

\section{Materials and Design}

Fifty-four pictures (18 pleasant, 18 neutral and 18 unpleasant) were selected from the International Affective Picture System (IAPS, Lang, Bradley, \& Cuthbert, 2008), on the basis of the Spanish normative pleasure and arousal ratings (Moltó et al., 1999; Vila et al., 2001) 2 . Pleasant (erotic couples) and unpleasant pictures (threatening scenes: guns, animal attacks) were extreme in valence, as well as extreme and equidistant from neutral stimuli (household objects) in arousal ratings.

Three slides of different geometric shapes (a triangle, a square, or a circle, over a white background) were used to cue the upcoming presentation of a specific category of pictures (erotica, household objects, or threatening scenes), counterbalanced across participants. Pairings of a geometric shape and an affective picture were formed, arranged in 6 blocks of 9 trials ( 3 exemplars of each picture content), randomly presented within a block. Each trial consisted of a 6-s of anticipatory interval (during which one of the three geometric shapes was continuously presented), immediately followed by a 6-s perception period (in which an affective picture in the cued category was presented).

Pictures were displayed using a Kodak Ektapro 9010 projector situated adjacent to the experimental room, on a slide screen approximately $2 \mathrm{~m}$ in front of the participant. Startle responses were elicited by a $105-\mathrm{dB}$, 50-ms burst of white noise, with instantaneous rise time, produced by a Coulbourn S81-02 noise generator, gated through a Coulbourn S82-24 amplifier, and presented over matched Telephonics TDH-49P headphones. In the last 3 blocks of the task, startle probes were delivered 3800 or $4500 \mathrm{~ms}$ after slide onset (9 probes during anticipation, 9 during perception, and 9 during both periods). Six additional probes were delivered during the inter-trial intervals that ranged from 15 to 20 seconds.

Participants were informed that two different groups of images would be presented during the task (geometric shapes and affective pictures), with each trial consisting of one stimuli from the first group (i.e., a triangle, circle or square) immediately followed by another stimuli from the second group (i.e., a neutral, erotic or threatening scene). However, they were not explicitly informed about which specific geometric shape would

\footnotetext{
${ }^{2}$ IAPS numbers used in this experiment were: Unpleasant --1300, $1303,1930,1932,6190,6200,6210,6230,6242,6243,6244,6250,6260$, 6300, 6370, 6410, 6510, 6570; Neutral --7004, 7006, 7009, 7010, 7020, 7025, 7031, 7035, 7040, 7060, 7150, 7170, 7175, 7217, 7224, 7235, 7700, 7950; Pleasant --4607, 4608, 4651, 4652, 4656, 4658, 4659, 4660, 4664, $4669,4670,4672,4676,4677,4680,4687,4689,4800$.
} 
signal the upcoming specific emotional category: They were expected to learn this relationship being exposed to pairings of both groups of stimuli during the first half of the task. No probes were delivered during these earlier 27 trials that were used to make participants aware of stimuli relationships. The latter 27 trials were used to test the startle reflex modulation and the electrodermal reactivity pattern during anticipation and perception of emotional pictures. Three presentation orders were arranged between participants, such that the 3 blocks within each half of the task were randomly presented at the first, second, or third position. In addition, two sets of 27 affective pictures were arranged, such that each set of pictures was randomly presented at the first half (learning trials) or at the second half (test trials) of the task, counterbalanced across participants.

\section{Physiological Recording and Data Reduction}

Stimulus control and physiological data acquisition were accomplished using a Compaq V70-compatible computer (VPM software: Cook, 2000).

Skin conductance activity was recorded through standard Coulbourn $\mathrm{Ag} / \mathrm{AgCl}$ electrodes (K-Y lubricating jelly), placed on the medial phalanges of the left hand index and middle fingers, using a Coulbourn V71-23 Isolated Skin Conductance Coupler. Phasic reactions in skin conductance were determined by subtracting activity in $1 \mathrm{~s}$ before the geometric slide onset from that occurring at each half-second after picture onset. Skin conductance change was defined as the largest change score occurring between 0.5 and $4 \mathrm{~s}$ after picture onset. Logarithms of raw scores, log [change + 1], were computed for statistical analyses.

Eyeblinks were recorded electromyographically from orbicularis oculi muscle with Coulbourn Ag/AgCl electrodes. Raw EMG signals were amplified (50K) and bandpass filtered (90-1000 Hz), using a Coulbourn V75-04 High Gain Bioamplifier, then rectified and integrated using a Coulbourn V76-23 Contour Following Integrator (time constant $125 \mathrm{~ms}$ ). The sampling rate was $1000 \mathrm{~Hz}$, beginning $50 \mathrm{~ms}$ prior to probe onset and sustained for $350 \mathrm{~ms}$. An interactive computer program scored startle blink magnitude peak and onset latency. Raw values were standardized ( $z$-scores) across all probed trials, within individuals, and transformed to $t$-scores. This transformation preserved the relationship among responses within individuals, but established a common metric across participants (cf. Blumenthal et al., 2005).

\section{Procedure}

Sensors were attached while participants reclined in a comfortable armchair, in an indirectly lighted, separate room of the laboratory. Participants were instructed to look at the pictures the entire time they were on the screen, and to ignore occasional noises presented over the headphones. In order to maximize their attention, they were told that a geometric figure slide would always be followed by an erotic couple slide, a household object slide, or a threatening scene slide, and each geometric shape would signal a different affective category. The relationship between signal and pleasant, neutral, or unpleasant pictures, however, was not specified. Picture trials began after a 2-minute baseline.

Following the session, participants completed a postexperimental questionnaire where they were asked about the purpose of the experiment as a measure of their awareness of the contingency relationship between each geometric shape and its corresponding affective category. Afterwards, pictures were displayed again on a computer (6-s each) and participants rated their emotional reactions to each picture (affective valence/ arousal) using the Self-Assessment Manikin (SAM; Bradley \& Lang, 1994).

\section{Data Analysis}

Two 3 (Picture Content: pleasant, neutral, unpleasant) repeated measures ANOVA were conducted on affective valence and arousal ratings, one for each dimension. A 2 (Processing Period: anticipation, perception) x 3 (Picture Content) repeated measures ANOVA was performed on startle blink magnitude. Skin conductance changes were analyzed with a 2 (Processing Period) x 3 (Picture Content) repeated measures ANOVA, selecting only those trials unaffected by probe presentation (i.e., probed and nonprobed trials during anticipation, plus perception trials not affected by probes presented during anticipation $)^{3}$. Greenhouse-Geisser corrections were used to control for all effects involving repeated measures.

\footnotetext{
${ }^{3}$ Because skin conductance is a slow response with onset latency around $1-3 \mathrm{~s}$ and here we measured the largest change score occurring between 0.5 and $4 \mathrm{~s}$ after picture onset, we expected that probes presented during anticipation (4500 or $3800 \mathrm{~ms}$ after picture onset) could affect electrodermal activity during perception but not anticipation periods. To examine whether probe presentation affected or not skin conductance changes to visual stimuli, separated repeated measures ANOVAs including Probe (probed vs. non-probed trials) were performed on anticipation and perception periods. Results showed that the main effect of Probe, $F(1,112)=103.33, p<.0001$, as well as its interaction with Picture Content, $F(2,224)=18.71, p<.0001$, were indeed significant during picture perception, but not during anticipation, Fs $<1$. Therefore, all the 27 anticipatory trials entered in the reported analyses but 4 perception trials of each picture content were excluded from the analyses (i.e., those clearly affected by probes presented during the preceding anticipatory period), leaving 15 trials for this condition.
} 


\section{Results}

\section{Affective Ratings}

Pleasure and emotional arousal ratings differed significantly over Picture Content, $F s(2,218)=417.83$ and 258.07 , respectively, $p s<.0001$. Pleasant pictures (6.69) were rated more pleasant than neutral (5.02) and unpleasant (2.69), linear trend $F(1,218)=828.32$, $p<.0001$. Arousal ratings for pleasant (5.65) and unpleasant (5.80) pictures were greater than for neutral (2.47), quadratic trend $F(1,218)=515.25, p<.0001$.

\section{Startle Reflex}

Overall patterns of startle reflex modulation during anticipation and perception

Table 1 shows descriptive statistics for startle blink magnitude in all experimental conditions. Startle blink magnitude varied across the two processing periods, $F(1,100)=4.73, p<.04$, being slightly greater during anticipation (50.80) than perception (50.06). In addition, modulation of the startle reflex magnitude as a function of picture valence differed in anticipation and perception, Processing Period $\mathrm{x}$ Picture Content $F(2,200)=14.86, p<.0001$.

During perception, startle blink magnitude differed significantly across the three picture contents, $F(2,200)=$ 29.24, $p<.0001$, with larger blinks when processing unpleasant, compared to pleasant, pictures, linear $F(1,200)=52.67, p<.0001$. Blinks were also significantly inhibited when viewing pleasant, compared to neutral, pictures, $F(1,200)=32.66, p<.0001$. Blink magnitude was greater for unpleasant pictures, compared to neutral stimuli, but this difference failed to reach statistical significance, $F(1,200)=2.38, p=.12$.

During anticipation, startle reflex was also related to picture content, $F(2,200)=3.60, p<.03$, with significantly reduced blinks when anticipating either pleasant or unpleasant pictures, compared to neutral stimuli, quadratic $F(1,200)=7.07, p<.009$. Specifically,

Table 1. Mean (standard error) startle blink magnitude and skin conductance changes during anticipation and perception of pleasant, neutral, and unpleasant pictures (test trials)

\begin{tabular}{lccc}
\hline Measure & Pleasant & Neutral & Unpleasant \\
\hline & & & \\
$\begin{array}{l}\text { Startle reflex } \\
\quad \text { Anticipation }\end{array}$ & $50.43(.42)$ & $51.75(.42)$ & $50.21(.38)$ \\
$\quad$ Perception & $47.34(.37)$ & $50.93(.44)$ & $51.90(.44)$ \\
& & & \\
Skin conductance & & & \\
$\quad$ Anticipation & $0.013(.002)$ & $0.009(.002)$ & $0.012(.002)$ \\
$\quad$ Perception & $0.013(.003)$ & $0.008(.002)$ & $0.011(.002)$ \\
\hline
\end{tabular}

unpleasant vs. neutral pictures, $F(1,200)=6.18, p<.02$ pleasant vs. neutral pictures, $F(1,200)=4.50, p<.04$; and unpleasant vs. pleasant, $F<1$.

Contingency awareness effects for startle modulation patterns during anticipation

In order to explore in depth the above results, additional analyses were performed with two groups of participants (72 fully aware vs. 16 unaware of cueaffective categories contingency) based on their reports in the post-experimental questionnaire. No effects of contingency awareness were found (all interactions Fs $<1$; specifically, Processing Period $x$ Picture Content $x$ Contingency Awareness, $p=.52$ ).

\section{Skin Conductance Changes}

\section{Overall patterns of electrodermal reactivity during anticipation and perception}

Mean skin conductance changes in each experimental condition are shown in Table 1. Skin conductance changes varied with Picture Content, $F(2,224)=3.76$, $p<.03$, with heightened responses during emotional arousing images, pleasant $(0.013 \mu \mathrm{S})$ or unpleasant $(0.012 \mu \mathrm{S})$, compared to neutral slides $(0.008 \mu \mathrm{S})$, $F(1,224)=7.01, p<.001$ and $F(1,224)=3.79, p<.05$, respectively, quadratic $F(1,224)=7.04, p<.01$. The interaction between Picture Content and Processing Period was indeed not significant $(F<1)$, suggesting that sympathetic activity over picture content did not vary across both processing periods ${ }^{4}$. No significant differences were found between anticipation and perception of emotional arousing or neutral pictures, all $F_{\mathrm{S}}<1$.

\section{Contingency awareness effects for electrodermal reactivity} during anticipation

Additional analyses were similarly performed on skin conductance changes with two groups of participants based on their post-experimental reports concerning awareness of cue-picture relationships. Though the uneven size of both subsamples (80 fully aware vs. 20 unaware participants) precluded us from finding

\footnotetext{
${ }^{4}$ As expected, no differences among cues predicting emotional vs. neutral pictures were found during anticipation in the first half of the task (quadratic trend $F<1$; mean skin conductance changes for pleasant, neutral, and unpleasant cues were 0.010, 0.009, and $0.008 \mu \mathrm{S}$, respectively). Posthoc comparisons between anticipatory periods of both learning (first half) and test trials (second half) also revealed differences for cues signaling upcoming unpleasant and pleasant pictures $(F(1,224)=6.76, p<.02$ and $F(1,224)=3.00, p=.08)$, but not for those cues signaling neutral stimuli, $F<1$. Overall, these results suggest that sympathetic reactivity increased across the experiment for both cues predicting emotionally arousing contents as a result of contingency learning, therefore reflecting that appropriate associations between cues and emotional pictures had been already learned in the second half of the experiment.
} 
significant effects or interactions in the omnibus ANOVA, contingency awareness seemed to be critical for skin conductance changes, Processing Period $x$ Picture Content $x$ Contingency awareness, $F(2,196)=2.96$, $p<.07$. Briefly, analogous results to those reported above were found for fully aware participants, with the main effect of Picture content, $F(2,158)=3.11, p<.05$, revealing greater changes for emotionally arousing, compared to neutral categories that show quadratic $F(1,158)=5.86, p<.02$. The interaction between Picture Content and Processing Period was again not significant $(p=.25)$, indicating similar sympathetic reactivity across perception and anticipation periods. However, for participants unaware of this relationship no effects of picture content on electrodermal reactivity were found during anticipation in the second part of the experiment, $F \mathrm{~s}<1$. When comparing responses during anticipatory periods of both learning and test trials, moreover, no significant differences were found for emotional or neutral pictures, $F \mathrm{~s}<1$, suggesting that sympathetic reactivity during anticipation did not change across the experiment for unaware participants.

\section{Discussion}

The purpose of this study was to explore the processing mediating anticipation of pleasant, neutral, and unpleasant stimuli in an attempt to determine the impact of the emotional valence (affect) and arousal (attention) on anticipatory startle responses. As compared to prior research focused on anticipation of emotional events, we introduced an important methodological variation that added some degree of uncertainty/difficulty and provided more ecological validity to the task. Here, participants had to learn by themselves the specific relations between a priori neutral cues (geometrical shapes) and emotional picture categories based on pairings during the first part of the experiment (learning trials), rather than being explicitly instructed about these relationships before the session began. Despite remarkable similarities with the affective picture-picture learning paradigm used by Lipp and colleagues (cf. Mallan \& Lipp, 2007; Mallan et al., 2008), our experimental procedure was not aimed to examine conditioning/learning effects on extinction but to explore anticipatory and perceptual processing of emotional stimuli in the second part of the experiment (i.e., after learning cue-picture contingencies).

As expected, a significant linear trend across picture contents was found during perception, with smaller blink magnitude during viewing of pleasant pictures (erotic scenes), and larger when viewing unpleasant images (threatening scenes). According to the motivational priming hypothesis, the observed affective modulation of the startle responses during perception reflected the activation of appetitive and defensive motivational systems, respectively (Lang et al., 1997). In addition, the larger skin conductance changes prompted by emotionally relevant stimuli, and corroborated by the subjective arousal ratings obtained in a subsequent evaluative task, reflected the enhanced physiological activation during perception of pleasant and unpleasant pictures, compared to neutral stimuli. In general, these results add further evidence that affective pictures are strong enough to engage the appetitive and defensive motivational systems, prompting emotional reactions in self-report, and physiological behavioral systems (e.g., Lang et al., 1993).

The lack of a significant blink potentiation during perception of unpleasant vs. neutral stimuli paralleled results of prior research exploring anticipatory processing of affective pictures (cf. Sabatinelli et al., 2001; Sege et al., 2011). To this extent, Sege, Bradley, and Lang (2013) have recently reported weaker emotional modulation of the startle response for cued pictures (preceded by a color signaling the upcoming thematic content), as compared to non-cued scenes. Likewise in our study, participants failed to show a significant potentiation during perception of cued unpleasant pictures, including also attack scenes. According to these authors, anticipatory processing might indeed attenuate the emotional impact of an event, consistent with prior classical conditioning work showing reduced response to an aversive UCS when it is reliably signaled (cf. Ison, Sanes, Foss, \& Pinckney, 1990).

In the current study, nevertheless, startle magnitude was reduced during anticipation of pleasant and unpleasant pictures, in comparison to neutral stimuli, even though the level of physiological activation was again significantly related to the arousal of the upcoming affective picture category, as reflected by the enhanced electrodermal changes during anticipation of emotional, compared to neutral, pictures. This unpredicted result did not replicate findings reported by prior studies examining the anticipation of emotionally salient, arousing pictures, which have generally found larger blink responses to emotional than to neutral stimuli (Dichter et al., 2002; Lipp et al., 2001; Nitschke et al., 2002; Sabatinelli et al., 2001), or eventually larger responses to unpleasant than to pleasant pictures -interpreted as the affective startle modulation typically found during perception (Allen et al., 1996; Erickson et al., 1995).

The discrepancy between the present data and previous studies might be explained by the absence of explicit verbal instructions about the contingency between signals and the forthcoming emotional picture categories, which might have added further " $c o g$ nitive load" to the passive picture viewing task, affecting eyeblink magnitude results. Indeed, there is evidence 
to suggest that startle response is attenuated when attention is directed to a different modality than the startle probe (Schicatano \& Blumenthal, 1998), particularly when the task to be completed in this modality is complex (Neumann, 2002). Similarly, less potentiation has been found when subjects were engaged in a demanding cognitive task (Vytal, Cornwell, Arkin, \& Grillon, 2012). In our study, participants were expected to learn by themselves the relationship between the formerly neutral cues and the emotional content depicted by the picture. Consequently, it could be argued that they had to dedicate additional cognitive effort to the processing of those cues signaling of either pleasant or unpleasant emotionally arousing categories in comparison to the neutral one. This supplementary cognitive load would leave less resources to respond to the noise probes thus evoking smaller blinks, likewise prior results with RT tasks or when probes are delivered within the first few milliseconds of picture viewing (i.e., prepulse inhibition; for a review, Blumenthal, 1999; Bradley, Codispoti \& Lang, 2006; Bradley et al., 1999).

Another hypothesis would be that the anticipation of an arousing stimulus might not lead to startle facilitation in the absence of anticipatory imagery (Lipp et al., 2001). Hence participants might not have successfully engaged in "anticipatory imagery" of the pending stimulation because they did not learn the contingency between cues and picture categories, which was not explicitly indicated at the start of the experiment, or because they had to learn (and remember) this relationship along the task. However, this hypothesis should be refused based on the post-experimental query completed afterwards, as approximately $71 \%$ of the overall sample was able to correctly report the cue-picture contingencies in a follow-up questionnaire. Additionally, partial analyses conducted on the subsample of participants fully aware of this contingency showed identical results to those described above. These thoughtprovoking results are consistent with previous conditioning findings showing that startle reflex is a good psychophysiological index of emotional learning in humans (e.g., Hamm \& Weike, 2005; Hamm, Greenwald, Bradley, \& Lang, 1993), thus demonstrating that this sort of automatic, implicit knowledge learned in an incidental manner (even when require a certain minimal amount of attention) seems to be independent of the post-experimental cue-picture contingency reports (e.g., Pastor et al., 2013). In addition, after training trials, subjects responded with enhanced skin conductance changes either when anticipating the upcoming emotionally arousing picture categories (i.e., threatening and erotica scenes) or perceiving this stimulation, revealing that a reliable relationship between cues and emotional pictures had been established. Nonetheless, that was true only for the completely aware subsample, suggesting that associative or relational learning (i.e., the capacity to explicitly learn that two or more events in the world are related to one another) does explicitly require contingency awareness, likewise in prior conditioning studies (for a review, Mitchell, De Houwe, \& Lovibond, 2009).

Extant studies using pictures as emotionally salient, anticipated stimuli have similarly led to equivocal results difficult to integrate, reflecting procedural differences across studies related to task requirements, signals used as cues, stimulus duration, probe positions, and time delay from cue to picture onset (i.e., delay vs. trace learning). Another important difference compared with preceding studies, suitable of further investigation, concerns the experimental sample. Here participants were unselected female college students, whereas some of previous studies tested those anticipatory effects on male samples with some anxiety disorder, either snake phobic students or participants diagnosed with anxious apprehension (e.g., Nitschke et al., 2002; Sabatinelli et al., 2001). Therefore, it could be interesting to further explore whether the present results during anticipation of emotional picture categories -obtained in a sample of undergraduate women non-selected by means of specific personality traits - might be generalized across gender and replicated in clinical samples, or even with another pleasant or unpleasant picture contents (e.g., thrill scenes, mutilations). Because many studies have demonstrated the influence of specific thematic contents over different peripheral measures and clinical populations (e.g., Bradley, Codispoti, Cuthbert, \& Lang, 2001; Bernat, Patrick, Benning, \& Tellegen, 2006; Levenston, Patrick, Bradley, \& Lang, 2000), it seems reasonable that future experiments ought to include additional picture categories to overcome the limited generalization of our current findings. Likewise, prior results obtained specifically for male samples with some anxiety disorder -besides precise picture contents- should be also generalized to female and normal population, aiming to provide more insights regarding the intriguing world of emotional expectancy, the anticipatory processing and its relationship with the emotional perception. Consequently, a systematic revision of previous literature focused on the experimental samples (in terms of gender or specific individual traits) would be particularly appropriated in order to explain the variety of startle eyeblink results during anticipation of emotional stimuli.

Finally, further research should also explore the contribution of awareness of contingency between cues and emotional pictures on the anticipation of emotional arousing stimuli for the startle blink, and particularly for the skin conductance changes. To this extent, our 
results parallel somehow those reported using aversive conditioning paradigms where the acquisition of CS+/UCS associations (as measured by fear-startle potentiation) does not necessarily require contingency awareness, suggesting that this emotional learning is automatic and obligatory. However, the relational or associative learning that occurs at the cognitive level (indexed by greater electrodermal changes for CS+ vs. CS-) is only effective when the participants learn that the CS+ predicts the occurrence of the UCS (Hamm \& Weike, 2005; Mitchell et al., 2009). Accordingly, it could be interesting to determine whether this absence of requirements of contingency awareness at the emotional level of learning (i.e., when neutral cues gain the affective properties to activate the corresponding aversive or appetitive system) might be connected to the development of affective disorders (e.g., phobias, generalized anxiety disorder, PTSD), mainly related to an abnormal functioning of the aversive motivational system (Lang, Davis, \& Öhman, 2000).

\section{References}

Allen N. B., Wong S., Kim Y., \& Trinder J. (1996). Startle reflex and heart rate responses during appetitive and aversive anticipation. Psychophysiology, 33, S18. http:/ /dx. doi.org/10.1111/j.1469-8986.1996.tb02380.x

Bermpohl F., Pascual-Leone A., Amedi A., Merabet L. B., Fregni F., Gaab N., ... Northoff G. (2006). Attentional modulation of emotional stimulus processing: An fMRI study using emotional expectancy. Human Brain Mapping, 27, 662-677. http:/ /dx.doi.org/10.1002/hbm.20209

Bernat E., Patrick C. J., Benning S. D., \& Tellegen A. (2006). Effects of picture content and intensity on affective physiological response. Psychophysiology, 43, 93-103. http:/ / dx.doi.org/10.1111/j.1469-8986.2006.00380.x

Blumenthal T. D. (1999). Short-lead-interval startle modification. In M. E. Dawson, A. Schell, \& A. Böhmelt (Eds.), Startle modification: Implications for neuroscience, cognitive science, and clinical science (pp. 51-71). Stanford, CA: Cambridge University Press. http:/ /dx. doi.org/10.1017/CBO9780511665523.005

Blumenthal T. D., Cuthbert B. N., Filion D. L., Hackley S., Lipp O. V., \& Van Boxtel A. (2005). Committee report: Guidelines for human startle eyeblink electromyographic studies. Psychophysiology, 42, 1-15. http:/ / dx.doi.org/ 10.1111/j.1469-8986.2005.00271.x

Bradley M. M., \& Lang P. J. (1994). Measuring emotion: The self-assessment manikin and the semantic differential. Journal of Behavior Therapy and Experimental Psychiatry, 25, 49-59. http://dx.doi.org/10.1016/00057916(94)90063-9

Bradley M. M., Codispoti M., \& Lang P. J. (2006). A multi-process account of startle modulation during affective perception. Psychophysiology, 43, 486-497. http:/ / dx.doi.org/10.1111/j.1469-8986.2006.00412.x

Bradley M. M., Codispoti M., Cuthbert B. N., \& Lang P. J. (2001). Emotion and motivation I: Defensive and appetitive reactions in picture processing. Emotion, 1 , 276-298. http://dx.doi.org/10.1037/1528-3542.1.3.276

Bradley M. M., Cuthbert B. N., \& Lang P. J. (1999). Affect and the startle reflex. In M. E. Dawson, A. Schell, \& A. Böhmelt (Eds.), Startle modification: implications for neuroscience, cognitive science and clinical science (pp. 157-183). Stanford, CA: Cambridge University Press. http://dx.doi.org/10.1017/CBO9780511665523.010

Bradley M. M., Moulder B., \& Lang P. J. (2005). When good things go bad: The reflex physiology of defense. Psychological Science, 16, 468-473.

Bradley M. M., Silakowski T., \& Lang P. J. (2008). Fear of pain and defensive activation. Pain, 137, 156-163. http:/ /dx.doi.org/10.1016/j.pain.2007.08.027

Cook E. W. III (2000). VPM reference manual. Birmingham, UK: Autor.

Cook E. W. III, Davis T. L., Hawk L. W., Spence E. L., \& Gautier C. H. (1992). Fearfulness and startle potentiation during aversive visual stimuli. Psychophysiology, 29, 633-645. http:/ /dx.doi.org/10.1111/j.1469-8986.1992. tb02038.x

Dawson M. E., Schell A., \& Böhmelt A. (Eds.). Startle modification: Implications for neuroscience, cognitive science, and clinical science. Stanford, CA: Cambridge University Press. http:/ /dx.doi.org/10.2277/0521580463

Dichter G. S., Tomarken A. J., \& Baucom B. (2002). Startle modulation before, during, and after exposure to emotional stimuli. International Journal of Psychophysiology, 43, 191-196. http:/ / dx.doi.org/10.1016/S01678760(01)00170-2

Erickson L. M., Levenson G. K., Curtin J. J., Goff A. B., \& Patrick C. J. (1995). Affect and attention in startle modulation: Picture perception and anticipation. Psychophysiology, 32, S30. http:/ /dx.doi.org/10.1111/ j.1469-8986.1995.tb02379.x

Grillon C., \& Ameli R. (1998). Effects of threat and safety signals on startle during anticipation of aversive shocks, sounds or airblasts. International Journal of Psychophysiology, 28, 223-231. http:/ / dx.doi.org/10.1016/S01678760(97)00072-X

Grillon C., Ameli R., Merikangas K., Woods S. W., \& Davis M. (1993). Measuring the time course of anticipatory anxiety using the fear-potentiated startle reflex. Psychophysiology, 30, 340-346. http://dx.doi. org/10.1111/j.1469-8986.1993.tb02055.x

Grillon C., Ameli R., Woods S. W., Merikangas K., \& Davis M. (1991). Fear-potentiated startle in humans: Effects of anticipatory anxiety on the acoustic blink reflex. Psychophysiology, 28, 588-595. http://dx.doi.org/ 10.1111/j.1469-8986.1991.tb01999.x

Grillon C., \& Davis M. (1995). Acoustic startle and anticipatory anxiety in humans: Effects of monaural right and left ear stimulation. Psychophysiology, 32, 155-161. http:/ /dx.doi.org/10.1111/j.1469-8986.1995.tb03307.x

Hamm A. O., Greenwald M. K., Bradley M. M., \& Lang P. J. (1993). Emotional learning, hedonic change, and the startle probe. Journal of Abnormal Psychology, 102, 453-465. http:/ / dx.doi.org/10.1037/0021-843X.102.3.453

Hamm A. O., \& Weike A. I. (2005). The neuropsychology of fear learning and fear regulation. International Journal of 
Psychophysiology, 57, 5-14. http://dx.doi.org/10.1016/ j.ijpsycho.2005.01.006

Ison J. R., Sanes J. N., Foss J. A., \& Pinckney L. A. (1990). Facilitation and inhibition of the human startle blink reflexes by stimulus anticipation. Behavioral Neuroscience, 104, 418-429. http:/ / dx.doi.org/ 10.1037/0735-7044. 104.3.418

Lang P. J., Bradley M. M., \& Cuthbert B. N. (1997). Motivated attention: Affect, activation, and action. In P. J. Lang, R. F. Simons, \& M. Balaban (Eds.), Attention and orienting: Sensory and motivational processes (pp. 97-135). New Jersey, NJ: Erlbaum.

Lang P. J., Bradley M. M., \& Cuthbert B. N. (2008). International Affective Picture System (IAPS): Affective ratings of pictures and instruction manual. Technical Report A-7. Gainesville, FL: The Center for Research in Psychophysiology, University of Florida.

Lang P. J., Davis M., \& Öhman A. (2000). Fear and anxiety: Animal models and human cognitive psychophysiology. Journal of Affective Disorders, 61, 137-159. http: / / dx.doi. org/10.1016/S0165-0327(00)00343-8

Lang P. J, Greenwald M. K., Bradley M. M., \& Hamm A. O. (1993). Looking at pictures: Affective, facial, visceral and behavioral reactions. Psychophysiology, 30, 261-273. http:/ / dx.doi.org/10.1111/j.1469-8986.1993.tb03352.x

Levenston G. K., Patrick C. J., Bradley M. M., \& Lang P. J. (2000). The psychopath as observer: Emotion and attention in picture processing. Journal of Abnormal Psychology, 109, 373-385. http:/ /dx.doi.org/10.1037/0021-843X.109.3.373

Lipp O. V., Cox D., \& Siddle D. A. T. (2001). Blink startle modulation during anticipation of pleasant and unpleasant stimuli. Journal of Psychophysiology, 15, 155-162. http://dx.doi.org/10.1027//0269-8803.15.3.155

Mallan K. M., \& Lipp O. V. (2007). Does emotion modulate the blink reflex in human conditioning? Startle potentiation during pleasant and unpleasant cues in the picture-picture paradigm. Psychophysiology, 44, 737-748. http:/ / dx.doi.org/10.1111/j.1469-8986.2007.00541.x

Mallan K. M., Lipp O. V., \& Libera M. (2008). Affect, attention, or anticipatory arousal? Human blink startle modulation in forward and backward affective conditioning. International Journal of Psychophysiology, 69, 9-17. http://dx.doi.org/10.1016/j.ijpsycho. 2008.02.005

McTeague L. M., Lang P. J., Laplante M. C., Cuthbert B. N., Shumen J. R., \& Bradley M. M. (2010). Aversive imagery in posttraumatic stress disorder: Trauma recurrence, comorbidity, and physiological reactivity. Biological Psychiatry, 67, 346-356. http://dx.doi.org/10.1016/ j.biopsych.2009.08.023

Miller M. W., Patrick C. J., \& Levenston G. K. (2002). Affective imagery and the startle response: Probing mechanisms of modulation during pleasant scenes, personal experiences and discrete negative emotions. Psychophysiology, 39, 519-529. http:/ /dx.doi.org/10.1017/ S0048577202394095

Mitchell C. J., De Houwer J., \& Lovibond P. F. (2009). The propositional nature of human associative learning. Behavioral Brain Science, 32, 183-198. http:/ / dx.doi.org/ 10.1017/S0140525X09000855
Moltó J., Montañés S., Poy R., Segarra P., Pastor M. C., Tormo M. P., ... Vila J. (1999). Un nuevo método para el estudio experimental de las emociones: El International Affective Picture System (IAPS). Adaptación española. [A new method for the experimental study of emotions: The International Affective Picture System (IAPS): Spanish adaptation]. Revista de Psicología General y Aplicada, 52, 55-87.

Neumann D. L. (2002). Effect of varying levels of mental workload on startle eyeblink modulation. Ergonomics, 45, 583-602. http:/ / dx.doi.org/10.1080/00140130210148546

Nitschke J. B., Larson C. L., Smoller M. J., Navin S. D., Pederson A. J. C., Ruffalo D., ... Davidson R. J. (2002). Startle potentiation in aversive anticipation: Evidence for state but not trait effects. Psychophysiology, 39, 254-258. http:/ /dx.doi.org/10.1111/1469-8986.3920254

Pastor M. C., Bradley M. M., Rehbein M. A., Markus Junghöfer M., Mastria S., El-Hinnawi N., \& Lang P. J. (2013). Multi-trial and single-trial aversive learning: Skin and startle. Psychophysiology, 50, S56. http://dx.doi.org/ $10.1111 /$ psyp. 12120

Patrick C. J., \& Berthot B. D. (1995). Startle potentiation during anticipation of a noxious stimulus: Active versus passive response sets. Psychophysiology, 32, 72-80. http:/ / dx.doi.org/10.1111/j.1469-8986.1995.tb03408.x

Pavlov I. P. (1927). Conditioned reflexes: An investigation of the physiological activity of the cerebral cortex. Translated and Edited by G. V. Anrep. London, UK: Oxford University Press.

Poy R., López R., Pastor M. C., Segarra P., Montañés S., Moltó J., \& Lang P. J. (2007). Threat of shock during picture viewing: Peripheral correlates. Psychophysiology, 44, S88. http://dx.doi.org/10.1111/j.1469-8986.2007. 00588.x

Sabatinelli D., Bradley M. M., \& Lang P. J. (2001). Affective startle modulation in anticipation and perception. Psychophysiology, 38, 719-722. http://dx.doi.org/10.1111/ 1469-8986.3840719

Schicatano E. J., \& Blumenthal T. D. (1998). The effects of caffeine and directed attention on acoustic startle habituation. Pharmacology Biochemistry and Behavior, 59, 145-150. http:/ /dx.doi.org/10.1016/S0091-3057(97)00384-5

Sege C. T., Bradley M. M., \& Lang P. J. (2011). Anticipation, affect and attention: Central and peripheral processes. Psychophysiology, 48, S49-50. http:/ /dx.doi.org/10.1111/ j.1469-8986.2011.01259.x

Sege C. T., Bradley M. M., \& Lang P. J. (2013). Does knowing what's coming modulate emotional reactions? Psychophysiology, 50, S56. http://dx.doi.org/10.1111/ psyp. 12120

Simons R. F., Öhman A., \& Lang P. J. (1979). Anticipation and response set: Cortical, cardiac, and electrodermal correlates. Psychophysiology, 16, 222-233. http:/ /dx.doi. org/10.1111/j.1469-8986.1979.tb02982.x

Skolnick A. J., \& Davidson R. J. (2002). Affective modulation of eyeblink startle with reward and threat. Psychophysiology, 39, 835-850. http:/ /dx.doi.org/10.1111/ 1469-8986.3960835

Vila J., Sánchez M., Ramírez I., Fernández M. C., Cobos P., Rodríguez S., ... Moltó J. (2001). El Sistema Internacional 
de Imágenes Afectivas (IAPS): Adaptación española. Segunda parte [The International Affective Picture System (IAPS): Spanish adaptation. Second part]. Revista de Psicología General y Aplicada, 54, 635-657.

Vytal K., Cornwell B., Arkin N., \& Grillon C. (2012).

Describing the interplay between anxiety and cognition: From impaired performance under low cognitive load to reduced anxiety under high load. Psychophysiology, 49, 842-852. http:/ /dx.doi.org/10.1111/j.1469-8986.2012. 01358.x

Witvliet C. V., \& Vrana S. R. (2000). Emotional imagery, the visual startle, and covariation bias: An affective matching account. Biological Psychology, 52, 187-204. http:/ /dx.doi. org/10.1016/S0301-0511(00)00027-2 